\title{
Using Web Simulation for Teaching and Learning about Critical Care: New Times and New Solutions
}

\author{
José Granero-Molina ${ }^{1,2^{*}}$ \\ ${ }^{1}$ Nursing, Physiotherapy and Medicine Department, Faculty of Education Sciences, Nursing and Physiotherapy, University of Almeria, Spain \\ ${ }^{2}$ Associate Researcher, Faculty of Health Sciences, Universidad Autónoma de Chile, Temuco, Chile
}

"Corresponding author: José Granero-Molina, Nursing, Physiotherapy and Medicine Department. Almería University, Carretera Sacramento, S/N , La cañada de San Urbano (04120), Almería, Spain, E-mail: jgranero@ual.es

Received date: Feb 04, 2015, Accepted date: Feb 06, 2015, Published date: Feb 13, 2015

Copyright: @ 2015 José Granero-Molina. This is an open-access article distributed under the terms of the Creative Commons Attribution License, which permits unrestricted use, distribution, and reproduction in any medium, provided the original author and source are credited.

\section{Editorial}

For many countries, the European Higher Education Area (EHEA) has led to the homogenization of university qualifications, regulating the transference of credits and student exchanges. However, it has also provided a framework for a critical analysis of teaching models and methodologies used in universities. Throughout this process, the Health Sciences Faculties (HSF), which teach subjects such as medicine, pharmacology, physiotherapy and nursing, have introduced alternative methodologies with the aim of increasing the quality of the teaching-learning processes. However, meeting the proposed improvement targets would not only mean lowering the professorstudent ration, but also, increasing investment in materials and technologies related to higher education. This situation thus supposes a paradox, as many countries in the European Union (EU) have made significant cuts to public investments in health and education. Although teaching innovation is essential, the process requires a renewal of tools, materials and methodologies, something which cannot always be done when facing an economic crisis.

Educators in the health sciences (HS) disciplines should focus teaching on the student, they should develop new learning processes and adapt their strategies to the variability of each context $[1,2]$. With regard to training nurses, the guidelines mean a commitment to new technologies, motivation and active participation from the students, theory-practice integration [3], distance learning [4] and simulation [5]. The incorporation of simulation exercises into nursing programs can provide many students with opportunities helping to improve learning outcomes. In the laboratory, activities related to the simulation of real-life problems allow students to not only strengthen theoretical knowledge but also to better understand the didactic materials, putting their knowledge into practice and recognizing errors, weaknesses and areas for improvement [6]. Students who prepare using simulations in the laboratory prior to carrying out clinical internships have a better understanding of their learning experience, clearly improving their response when later faced with any type of event in real life. In this sense, it is sometimes the students themselves who demand better theory-practice training, something which both professors and clinical tutors have considerable difficulties to provide [3].

This issue is made even more evident in the teaching and learning of necessary life-saving/preserving skills. The incorporation of simulators to support the teaching of Basic or Advanced Life Support (BLS/ALS) or care of critically ill patients is now a constant in our HSF. In the Advanced Cardiac Life Support (ACLS) laboratory, emergencies similar to those which may be encountered in real life are simulated which, being potentially life-threatening situations, require students to be trained in responding quickly. The students work in groups to recognize cases, diagnose them and take measures in the attempt to resolve said critical situations. Simulations allow the students to practice and demonstrate their skills related to Basic Life Support, ACLS algorithms, patient defibrillation, working in a team, prioritizing and communication [7]. Laboratory classes are eminently practical; to be carried out correctly, they require small groups of students, but this is not always possible. For this reason, we need to find imaginative solutions which strengthen student learning, such as employing web simulation when teaching the electrocardiogram (ECG).

All actions taken by the emergency teams in ACLS center around cardiac monitoring and the ECG diagnosis. Nurses are often the primary witnesses to these problems, and are fundamental in the training of professionals and students. Although the ECG has historically been taught in a traditional classroom, the lack of time and resources, together with the emergence of new technologies, has altered the teaching-learning process. Various technologies have been applied in the teaching of the ECG, from CD-ROMs, computer programs and computer-assisted tutorials to videograms and multimedia teaching [8]. However, the lack of conclusive results related to effectiveness, together with economic cost, is making web simulation more and more popular [9].

There are various ECG simulators which can be used via the web, such as The 6 Second ECG [10], an open-access web simulator which generates and allows for the learning of 27 of the common cardiac rhythms. Using the Explore-Review function, you can click on any rhythm name to display the rhythm and its description, while hovering the cursor over the rhythm freezes it. The Explore-Review-Play function allows for diagnosis of the ECG, setting the Game Time Period, Dynamic or Static Rhythm Display, Sound volume and Grid display beforehand. The system generates a report of the number of attempts, \% of correct answers, average diagnosis time, and practical recommendations. In the classroom stage of laboratory, the simulator allows cardiac rhythms to be projected, which can then be diagnosed by the student or group of students tackling the case, with the help of the professor and in the presence of the rest of the class. To complement these activities, in the non-classroom stage which is carried out at home, the students play, helping to improve their success rates or challenge each other to get the correct diagnosis. This nonclassroom activity supplements classroom learning, allowing the students to adapt their learning in relation to their own rhythm and needs.

Several studies have already demonstrated how effective employing this methodology in the HS disciplines can be. Students see the webbased ECG interpretation as a useful tool, with greater immediacy, 
visualization and interactivity than traditional teaching $[11,12]$. Websimulated ECGs improve the students' self-confidence and critical thinking [13], and together with personalized training, show good results in ACLS. Furthermore, other studies indicate that the effectiveness of this methodology in the interpretation of arrhythmias should be extended to the complete ECG [14,15], although it would be necessary to better explore its effects related to student learning outcomes, learning styles and strategies $[16,17]$.

Web simulation can be an excellent tool to complement student training both in the classroom and at home; it can be used as an effective supplement to laboratory training and education when faced with a lack of time or materials.

\section{References}

1. Shinnick MA, Woo MA, Mentes JC (2011) Human patient simulation: state of the science in prelicensure nursing. J NursEduc 50: 65-72.

2. Castro-Sánchez AM, Aguilar-Ferrándiz MA, Matarán-Peñarrocha GA, Iglesias-Alonso AA, Fernández-Fernández MJ, et al. (2012). Problem based learning approaches to the technology education of physical therapy students. MedTeach 34: 29-45.

3. Granero-Molina J, Fernández-Sola C, Castro-Sánchez AM, Jiménez-López FR, Aguilera-Manrique G, et al. (2012)The clinical seminar as a learning methodology: an evaluation of nursing students' views. Acta Paul.Enferm 25: 441-447.

4. Nguyen DN, Zierler B, Nguyen HQ (2011) A survey of nursing faculty needs for training in use of new technologies for education and practice. $J$ Nurs Educ 50: 181-189.

5. Hallenbeck VJ (2012) Use of high-fidelity simulation for staff education/ development: a systematic review of the literature. J Nurses Staff Dev 28 260-269.

6. McDavid L (2014) Enhancing learning through simulation activities. J Nurs Care 3: 6 .
7. Hernández-Padilla J, Suthers F, Fernández-Sola C, Granero-Molina J (2014) Development and psychometric assessment of the Basic Resuscitation Skills Self-Efficacy Scale. Eur J Cardiovasc Nurs.

8. Chang MH, Hsu LL (2010) [Multimedia instruction: its efficacy in nurse electrocardiography learning]. Hu Li Za Zhi 57: 50-58.

9. Cook N, McAloon T, O'Neill P, Beggs R (2012) Impact of a web based interactive simulation game (PULSE) on nursing students' experience and performance in life support training--a pilot study. Nurse Educ Today 32: 714-720.

10. SS-ECG (The six second ECG) ${ }^{\circ}$. SkillStat Learning Inc. North Vancouver, British Columbia, Canada.

11. Mahler SA, Wolcott CJ, Swoboda TK, Wang H, Arnold TC (2011) Techniques for teaching electrocardiogram interpretation: self-directed learning is less effective than a workshop or lecture. Med Educ 45: 347-353.

12. Nilsson M, Bolinder G, Held C, Johansson BL, Fors U, et al. (2008) Evaluation of a web-based ECG-interpretation programme for undergraduate medical students. BMC Med Educ 8: 25.

13. Brown D, Chronister C (2009)The effect of simulation learning on critical thinking and self-confidence when incorporated into an electrocardiogram nursing course. Clinical Simulation in Nursing 5: 45-52.

14. Mueller MP, Christ T, Dobrev D, Nitsche I, Stehr SN, et al (2005) Teaching antiarrhythmic therapy and ECG in simulator-based interdisciplinary undergraduate medical education. Br J Anaesth 95: 300-304.

15. Varvaroussis DP, Kalafati M, Pliatsika P, Castrén M, Lott C, et al. (2014) Comparison of two teaching methods for cardiac arrhythmia interpretation among nursing students. Resuscitation 85: 260-265.

16. Tawalbeh LI, Tubaishat A (2014) Effect of simulation on knowledge of advanced cardiac life support, knowledge retention, and confidence of nursing students in Jordan. J Nurs Educ 53: 38-44.

17. Lahti M, Hätönen H, Välimäki M (2014) Impact of e-learning on nurses' and student nurses knowledge, skills, and satisfaction: a systematic review and meta-analysis. Int J Nurs Stud 51: 136-149. 